\title{
Chromatographic studies of extractant residues in the chemical technology of carotenoid production
}

\author{
Volodymyr Gerasimenko $^{1}$, Svitlana Lysytska ${ }^{2}$ \\ ${ }^{1}$ Ukrainian State University of Chemical Technology, Gagarin Avenue, 8, Dnipro, Ukraine, \\ E-mail: gerasim_vlad@ukr.net \\ ${ }^{2}$ National TU Dnipro polytechnic, Dmitry Yavornitsky Avenue, 19, Dnipro, Ukraine, E-mail: 1svet050549@gmail.com
}

\begin{abstract}
Selected parameters of gas chromatographic analysis, which allow to determine and control the purity of industrial carotene preparations for nutrition and medicine purpose. It has been discovered that undesirable accumulation of chemical reagents in carotenoids in the course of a multi-stage and long-term biomaterial extraction mode requires additional purification from the residues of dangerous extractants.
\end{abstract}

Key words: chemical technology, carotenoids, gas chromatographic analysis, chemical extractants, toxicant residues

\section{Problem analysis}

Industrial forms of carotenoids have a wide range of applications in the fields of medicine and nutrition that are related to human health. These are nutritional supplements (dyes E160c, E160a, E160d); medicinal and pharmaceutical substances; supplements to the diet of animals and birds, components in cosmetology. Therefore, qualitative indicators of carotenoids marketable products are strictly regulated by sanitary-hygienic norms and standards of the State Pharmacopoeia of Ukraine. This approach is aimed at harmonizing the laws of Ukraine "On Medicines"; "On medicinal products" within the framework of regulatory documents of the European Pharmacopoeia, identical to international standards concerning the requirements of ICH, GMP [1,2]. The rules of the above-mentioned documents are focused on the safe level of purity of medicinal and nutrition products and other types of products. They provide for control and regulation of the content of residual quantities of chemical extractants using validated analytical methods. In this aspect, the solution to the problem of the selection of highly effective sensitive methods for detecting and controlling the level of harmful substances (in particular, organic volatile chemical compounds) in vital nutrition and medicinal substances is up-to-the-minute. Among the modern analytical methods, various types of chromatographic analysis are recognized as such [3, 4].

It is known that plant products include a group of yellow-orange liposoluble pigments different carotenoid isomers ( $\beta$-carotene, lycopene, lutein, zeaxanthin, etc.). The latter are components of plants (algae cells, herbs, shrubs, trees, many fruits and vegetables) and fungi. The biological activity of carotenoids occurs in many life processes: light and color perception, in antioxidant, immune stimulating, protect against cancer and adaptogenic actions, participation in regulation of differentiation and reproduction of cells, etc.

The structure of carotenoid molecules, in which structural isoprene units are interconnected in a long chain, determines their ability to transform enzymatically in the body of human and many animals into the retinal molecules (the precursor of vitamin A). This transformation mechanism determines the value of carotenoids as products for the nutrition, medical, pharmacological and other industrial sectors.

Carotenoids are synthesized by chemical and microbiological ways (based on bacterial cells, actinomycetes, yeast, filamentous fungi). At the same time, the most promising source of carotenoid pigments is the strain of mucorales heterothallic fungi Blakeslea trispora, capable of carotenogenesis through the course of complex enzymatic reactions in multicomponent nutrient media. To extract carotenoids from mycelial biomass, both pure organic solvents (hexane, acetone, methanol, propanol, methyl ethyl ketone, ethyl acetate, methylene chloride) and solvent mixtures - acetone: carbon tetrachloride (2-10:1); n-hexane: acetone (175:5), petroleum ether: tetrahydrofuran $(4: 1)$, chloroform: methanol $(2: 1)$ are used, and also vegetable oils for direct extraction from vegetable raw materials (carrot, pumpkin, sea buckthorn, alfalfa, etc.). 
Carotenoids of industrial biotechnological preparations based on Blacheslea trispora are represented by $90 \%$ of $\beta$-carotene and $10 \%$ by $10 \%-\alpha-, \gamma$-carotenes and lycopene.

Given that the mode of extraction of these carotenoids by chemical agents from fungi biomass is a multi-stage and long process, and for the manufacture of nutrition, pharmacopoeial and medical preparations, this technology requires additional purification of carotenoids with organic solvents [3], undesirable accumulation of the latter in the target substance is possible.

The purpose of the study is to develop a method for determining and conducting a quantitative analysis of toxicant residues - organic extractants of chemical nature using an accurate, sensitive analytical method, aimed at reducing environmental risks by improving the purity and quality of products for nutrition and prophylactic purposes.

\section{Study results}

As objects of research, industrial forms of dietary supplements were selected: $\beta$-carotene (E160a), lycopene (E160d), $\beta$-carotene oil and water soluble $\beta$-carotene, obtained by microbiological synthesis from fungi biomass of Blakeslea trispora. In a role of extractant, manufacturer used methylene chloride solvent stabilized with methanol.

According to the requirements of ICH on the toxicity of organic solvents in medicinal products, methylene chloride and methanol belong to 2nd class of hazard [1,2]. Methylene chloride is characterized by a narcotic effect, reaction of irritation of the mucous membranes of the eyes and respiratory organs, prolonged exposure destroys the liver, nervous and cardiovascular systems. Therefore, the content of methylene chloride in carotenoids should not exceed $0.03 \%$.

We investigated the direct gas chromatographic analysis of liquid and solutions of solid industrial forms of carotenoids. Assessment of the suitability as a solvent of a wide range of various chemical nature liquid substances (hydrocarbon aliphatic, aromatic, alcohols, ketones, esters) was carried out. The vast majority of investigated substances contain volatile impurities that appear on the chromatogram in the area of methylene chloride and prevent its quantitative determination. It has been found that the most suitable as a solvent for industrial forms of carotenoids can only be paraxylene and ethylbenzene.

The need to determine residual amounts of methylene chloride in carotenoid type biological preparations at the level of the requirements of international standards [1] requires the operation of a chromatographic detector in the most sensitive mode. This regulates stringent requirements for the thermal stability of the stationary phases of the separation system.

It has been established that among a wide range of stationary phases of different chromatographic polarity, only methyl and methylphenylsiloxanes correspond to this criterion.

The method of adding a reference to the analyte is most reliable in gas chromatography. The reference substance shall meet the following requirements: chloride;

- peak of the reference should appear on the chromatogram near the peak of methylene

- there should be a complete separation of the reference and methylene chloride peaks; reference should not contain impurities whose peaks coincide or are poorly separated from the peak of methylene chloride.

It has been found that these requirements are mostly consistent with isobutanol. Solutions of known concentrations of isobutanol and methylene chloride in paraxylene were used to determine the calibration factor. Subsequently, a solution of isobutanol was added to the solution of the industrial form of carotenoid and the content of methylene chloride was determined using the determined calibration factor.

Studies were performed on a chromatograph with a flame ionization detector.

Separation system:

$-3 \mathrm{~m}$ long column with an internal diameter of $3 \mathrm{~mm}$;

$-5 \%$ OV-17 sorbent on N-super-chromatone $0.16-0.20 \mathrm{~mm}$;

- sample volume $0.4-0.6 \mu \mathrm{l}$;

- column temperature $70^{\circ} \mathrm{C}$;

- sample evaporation temperature $200^{\circ} \mathrm{C}$. 
Determination of residual amounts of methylene chloride in carotenoids was carried out in four-, fivefold repeatability.

Results of statistical processing of the determination of methylene chloride content in some industrial samples of carotenoids are given in Tables 1 and 2.

Table 1 - Results of statistical processing of the determination of methylene chloride content in an industrial sample of $\beta$-carotene $(\mathrm{P}=0,95 ; \mathrm{n}=5)$

\begin{tabular}{|c|c|c|}
\hline $\begin{array}{c}\text { Measured concentration, } \\
\%\end{array}$ & $\begin{array}{c}\text { Average value } \\
(\mathrm{x} \pm 5), \%\end{array}$ & Permissible content, $\%$ \\
\cline { 1 - 1 } 0,167 & & \\
\cline { 1 - 1 } 0,168 & \multirow{2}{*}{$0,167 \pm 0,006$} & 0,03 \\
\hline 0,162 & & \\
\hline 0,163 & & \\
\hline 0,173 & & \\
\hline
\end{tabular}

Table 2 - Results of statistical processing of the determination of methylene chloride content in an industrial sample of lycopene $(\mathrm{P}=0,95 ; \mathrm{n}=4)$

\begin{tabular}{|c|c|c|}
\hline $\begin{array}{c}\text { Measured concentration, } \\
\%\end{array}$ & $\begin{array}{c}\text { Average value } \\
(\mathrm{x} \pm 5), \%\end{array}$ & Permissible content, $\%$ \\
\cline { 1 - 1 } 0,115 & \multirow{2}{*}{$0,111 \pm 0,004$} & 0,03 \\
\hline 0,112 & & \\
\cline { 1 - 1 } 0,109 & & \\
\hline 0,110 & & \\
\hline 0,111 & & \\
\hline
\end{tabular}

Obtained results indicate that the residual amount of methylene chloride in the B-carotene sample was $0,167 \%$, which exceeds the permissible concentration according to ICH requirements by 5,6 times, and the residual amount of methylene chloride in the lycopene sample was $0,111 \%$, which exceeds the permissible concentration in accordance with the requirements of the standard by 3,7 times.

\section{Conclusions}

Thus, the gas chromatographic analysis method developed by us makes it possible to effectively control the residual amount of extractant in carotenoids for both nutrition and medicinal purposes preparations, and the technology of their production requires additional purification from residues of hazardous chemical extractants.

\section{Reference}

[1] ICH Harmonized Guideline. Impurities: Guideline for residual solvents Q3C, 2016. https://www.ich.org/fileadmin/Public_Web_Site/ICH_Products/Guidelines/Quality/Q3C/Q3 C__R6 Step_4.pdf. [Accessed March 1, 2019].

[2] M.H. Levyn, V.N. Brytsun., R.A. Meleshko, O.N. Tereshchenko, A. A. Humeniuk, Ostanyna N.V. "Sovremennye aspekty normirovanyia y kontrolia profylia prymesei v lekarstvennykh preparatakh", Farmakolohiia ta likarska toksykolohiia, no 4-5 (60), pp. 74-88, 2018.

[3] Vytenberg A.H. Statycheskiy parofazniy hazokhromatohrafycheskiy analyz. "Fyzykokhimicheskie osnovy oblasti primenenia, Ros. khym. zh. (Zh. Ros. khym. ob-va ym. D.Y. Mendeleeva), vol. XLVII, no 1, pp. 7-22, 2003.

[4] Nykytchenko N.V., Platonov Y.A., Onuchak L.A. Ekstraktsyonno-khromatohrafycheskoe opredelenye kachestva lekarstvennoho rastytelnogo syria "Rastoropsha piatnystaia", Analitika i control, vol. 16, no 2, pp. 169-173, 2012. 